\title{
ERRATUM
}

\section{Self-Reference Effect and Self-Reference Recollection Effect for Trait Adjectives in Amnestic Mild Cognitive Impairment - Erratum}

Nicole Carson, R. Shayna Rosenbaum, Morris Moscovitch, AND Kelly J. Murphy doi: 10.1017/S1355617718000395. Published online by Cambridge University Press on 2 August 2018.

The paper by Carson et al. (2018) contains an error on page 821 that should be brought to the attention of readers. It is listed here, along with the incorrect and correct copy:

Incorrect copy: RECEIVED August 10, 2017; FINAL REVISION April 19, 2018; ACCEPTED May 1, 2018; FIRST PUBLISHED ONLINE August 2, 2018

Correct copy: RECEIVED August 10, 2017; FINAL REVISION April 19, 2018; ACCEPTED May 2, 2018; FIRST PUBLISHED ONLINE August 2, 2018

Cambridge University Press regrets the inconvenience that this error may have caused. The article has been updated with the correct copy. 